\title{
The effects of postoperative hematocrit on shunt occlusion for neonates undergoing single ventricle palliation
}

\author{
Brett R. Anderson, MD, MBA, MS, ${ }^{a}$ Victoria L. Blancha, BS, ${ }^{b}$ Jennifer M. Duchon, MDCM, MPH, ${ }^{c}$ \\ Paul J. Chai, MD, ${ }^{\mathrm{d}}$ David Kalfa, MD, PhD, ${ }^{\mathrm{d}}$ Emile A. Bacha, MD, ${ }^{\mathrm{e}}$ Ganga Krishnamurthy, MD, ${ }^{\mathrm{f}}$ and \\ Veniamin Ratner, $\mathrm{MD}^{\mathrm{f}}$
}

\begin{abstract}
Objectives: Our primary objective was to test the effects of first postoperative hematocrit on early shunt occlusion for children undergoing systemic to pulmonary artery shunt placement. Because any intervention to reduce shunt occlusion is only beneficial if it reduces mortality or is, at least, mortality neutral, we also tested the effects of first postoperative hematocrit on in-hospital mortality.

Methods: We conducted a retrospective study on all neonates who underwent primary systemic to pulmonary artery shunt placement, with or without a Norwood/Damus-Kaye-Stansel procedure, at Columbia University Medical Center between January 2010 and July 2015. Univariable regression was used to test the effects of first postoperative hematocrit on early shunt occlusion and 30-day mortality, clustering standard errors by surgeon. In secondary analyses, we also tested associations between red blood cell transfusion volumes in the first 24 postoperative hours and first postoperative hematocrit, shunt occlusion, and mortality.
\end{abstract}

Results: Eighty infants met inclusion criteria. Median initial postoperative hematocrit was $41.7 \%$ (interquartile range, 37.9-46.0). Six infants (7.5\%) died. Four infants $(5.0 \%)$ died within the first 30 days. Five infants $(6.3 \%)$ experienced early shunt occlusion. No children with early shunt occlusion died. In univariable models, for every 5 additional percentage points of hematocrit, an infant's odds of early shunt occlusion more than doubled (odds ratio, 2.70; $P=.009$ ). The odds of all-cause 30-day mortality remained unchanged.

Conclusions: Higher postoperative hematocrit levels are associated with early shunt occlusions in infants undergoing primary systemic to pulmonary artery shunt placement. Multicenter investigations are warranted to validate these findings and to determine ideal postoperative hematocrit targets for this population. (J Thorac Cardiovasc Surg 2017;153:947-55)

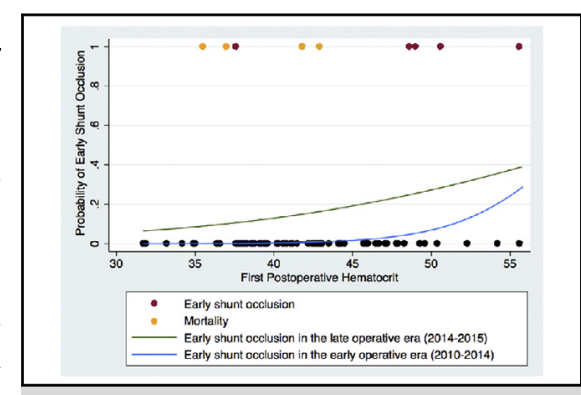

First postoperative hematocrit and early postoperative shunt occlusion.

\section{Central Message}

For neonates undergoing systemic to pulmonary artery shunts, higher hematocrit levels are associated with early shunt occlusion.

\section{Perspective}

A significant cause of systemic to pulmonary artery shunt failure in neonates is shunt occlusion. In a retrospective study of 80 infants, we found increased first postoperative hematocrit to be associated with early occlusion. Studies are needed to validate these results and determine ideal target hematocrits for this vulnerable population.

See Editorial Commentary page 956.
A significant cause of shunt failure in neonates after systemic to pulmonary artery shunt placement is shunt occlusion, yet little is known about why shunts occlude in

\footnotetext{
From the Divisions of ${ }^{\mathrm{a} P e d i a t r i c ~ C a r d i o l o g y}$ and ${ }^{\mathrm{f}}$ Neonatology, NewYork-Presbyterian/Morgan Stanley Children's Hospital, Columbia University Medical Center; ${ }^{\mathrm{b}}$ Columbia University College of Physicians and Surgeons; ${ }^{\mathrm{c}}$ Division of Pediatric Infectious Disease, NewYork-Presbyterian/Morgan Stanley Children's Hospital; Divisions of ${ }^{\mathrm{d}}$ Cardiothoracic Surgery and ${ }^{\mathrm{e}}$ Cardiothoracic Surgery, Columbia University College of Physicians and Surgeons, New York, NY.

Received for publication Dec 29, 2015; revisions received Sept 20, 2016; accepted for publication Sept 28, 2016; available ahead of print Dec 6, 2016.

Address for reprints: Brett R. Anderson, MD, MBA, MS, NewYork-Presbyterian/ Morgan Stanley Children's Hospital, 3959 Broadway, 2 North, New York, NY 10032-3784 (E-mail: bra2113@cumc.columbia.edu).

$0022-5223 / \$ 36.00$

Copyright (C) 2016 by The American Association for Thoracic Surgery http://dx.doi.org/10.1016/j.jtcvs.2016.09.085
}

some infants and not in others. ${ }^{1-7}$ It has been hypothesized that, in addition to shunt anatomy, ${ }^{7}$ fluid shifts and hemoconcentration might predispose children to shunt occlusion, especially after gastrointestinal surgeries, ${ }^{8}$ but the majority of shunt occlusions occur in the early postoperative period, without associated surgeries. 5,6

Beginning in the latter half of 2014, we noticed an increase in the incidence of early shunt occlusions in our

Scanning this QR code will take you to a video for the article.

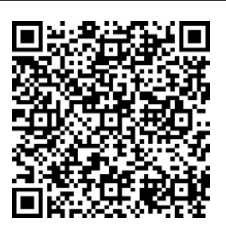




\section{Abbreviations and Acronyms \\ FFP = fresh-frozen plasma \\ $\mathrm{IQR}=$ interquartile range \\ $\mathrm{OR}=$ odds ratio \\ $\mathrm{PRBC}=$ packed red blood cell}

neonatal cardiac intensive care unit. We conducted a retrospective chart review to investigate the causes of this increase. Given that platelet adhesion in pulsatile shear flow is known to be significantly influenced by the concentration and characteristics of neighboring red blood cells, ${ }^{9,10}$ we hypothesized that increased hematocrit in the early postoperative period might be a cause of early shunt occlusion. Therefore, we set out to test the associations between first postoperative hematocrit and early shunt occlusion for children undergoing systemic to pulmonary artery shunt placement at our center. Because any intervention to reduce shunt occlusion is only beneficial if it reduces mortality or is, at least, mortality neutral, we also set out to test the associations between first postoperative hematocrit and in-hospital mortality.

\section{MATERIALS AND METHODS \\ Patients}

We performed a retrospective study, including all neonates who underwent systemic to pulmonary artery shunt placement at Columbia University Medical Center, with or without a Norwood/Damus-Kaye-Stansel procedure, between January 2010 and July 2015. These dates were chosen to include all data available in our clinical database at the onset of this study. Infants undergoing right ventricle to pulmonary artery shunt placement were not included. One child who underwent systemic to pulmonary artery shunt placement but who had an initial postoperative hematocrit of 66.8 and who consequently rapidly underwent partial exchange transfusion was excluded from the analysis. This study was approved by the Columbia University Medical Center Institutional Review Board, with waiver of informed consent.

\section{Operative and Perioperative Management}

At our institution, systemic to pulmonary artery shunts are placed by lateral thoracotomy or median sternotomy on the basis of patient cardiac anatomy and surgeon preference (see Video 1). Intraoperative fluid management includes continuation of maintenance fluids or addition of normal saline or Ringer's lactate as determined by the anesthesia team. All shunted infants leave the operating room intubated and are recovered in the neonatal cardiac intensive care unit. Choice of initial inotropic support is based on patient condition and anesthesiologist and surgeon preferences. In the perioperative period, all shunted patients receive intravenous maintenance fluids (of $100 \mathrm{~mL} / \mathrm{kg} \cdot \mathrm{d}$ ) with dextrose and standard electrolytes. Our current anticoagulation practice is to initiate oral aspirin approximately 12 hours after shunt placement (at a dose of $20 \mathrm{mg} / \mathrm{d}$ ), assuming the platelet count is greater than $100 \mathrm{~K}$ and surgical site bleeding is minimal. Until mid-2010, shunted infants at our center received aspirin, at the same dose, only after full enteral feeds were established. There was a brief time in early 2010 when shunted infants operated on by a single surgeon were given heparin after hemostasis was achieved, but none was started on heparin within the first 24 postoperative hours. Packed red blood cell (PRBC) transfusion thresholds are determined on an individual basis by patient condition and intensive care team discretion.

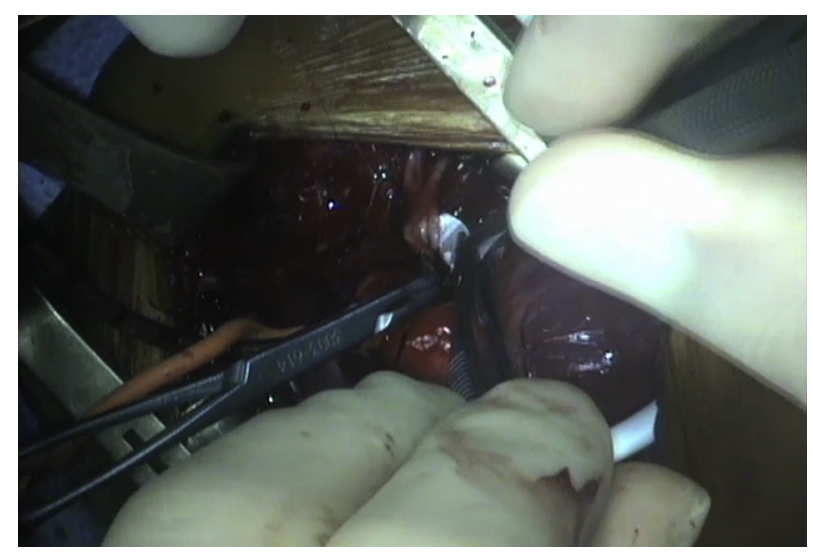

VIDEO 1. Blalock-Taussig shunt placement. The video details the placement of a Blalock-Taussig shunt as part of a single ventricle palliation. Video available at: http://www.jtcvsonline.org/article/S0022-5223(16) 31464-7/addons.

\section{Risk Factors}

The primary variable of interest was the first postoperative hematocrit on returning to the intensive care unit. All hematocrit levels were measured in our clinical laboratory using a Sysmex XN-9000 analyzer (Sysmex, Kobe, Japan), which calculates percent hematocrit using cumulative pulse height detection. Data also were collected on sex, weight, intracardiac anatomy, shunt type and size (first in millimeters and then indexed to birth weight), use of cardiopulmonary bypass, performance of a pulmonary artery plasty, intraoperative PRBC transfusion volume, fluid balance on pulmonary bypass, cell saver transfusion volume coming off bypass, arterial oxygen tension leaving the operating room, first postoperative platelet count, presence and volume of postoperative PRBC, platelets, and freshfrozen plasma (FFP)/cryoprecipitate transfusion administrations in the first 24 postoperative hours (or until shunt occlusion), type and timing of anticoagulation, peak vasoactive-inotropic score within the first 24 postoperative hours, surgeon, and operative era. Earlier operative era was defined as all patients undergoing operation before July 1, 2014; later operative era was defined as all patients operated on or after that date. Vasoactive-inotropic score was calculated using the formula previously described by Gaies and colleagues. ${ }^{11}$

\section{Outcomes}

The primary outcome of interest was early shunt occlusion within the first 24 postoperative hours requiring surgical intervention, including shunt revision, catheter intervention, or manual shunt manipulation. Infants with shunt occlusion determined on autopsy also were included. Shunt occlusion was presumed on the basis of the loss of a shunt murmur and inability to visualize shunt flow on echocardiogram in the presence of systemic desaturations and an acute decrease in end-title carbon dioxide without an identifiable pulmonary cause and with amelioration of symptoms after manual manipulation of the shunt or shunt revision. No patients with early shunt occlusion died before intervention. All patients had heparin boluses given, their chests opened, and shunts manually manipulated to relieve obstruction. Patients who did not recover after this manipulation were taken back to the operating room for immediate shunt exploration and revision and potential placement on extracorporeal membrane oxygenation. No shunts were observed to be kinked on visual inspection, and in no patients did the mere act of opening the chest relieve symptoms. Consideration also was given to diagnostic or therapeutic catheterization; 2 patients who had partial but not complete recovery after manual shunt manipulation were taken to the catheterization laboratory, where angiography was performed, demonstrating shunt narrowing without kinking, and shunts were stented. All patients recovered after shunt 
TABLE 1. Patient characteristics

\begin{tabular}{|c|c|c|c|}
\hline & $\begin{array}{c}\text { N }(\%) \text { mean/median } \\
(\mathrm{SD} / \mathrm{IQR})\end{array}$ & $\begin{array}{c}\text { Association with early } \\
\text { shunt occlusion ( } P \text { value })\end{array}$ & $\begin{array}{c}\text { Association with } \\
\text { 30-d mortality ( } P \text { value })\end{array}$ \\
\hline Male sex (female) & $33(40.7)$ & 1.000 & 1.000 \\
\hline Gestational age $<37 \mathrm{wk}$ & $39(18.7)$ & 1.000 & .849 \\
\hline SGA & $17(21.3)$ & .780 & .834 \\
\hline Cardiac anatomy & - & - & - \\
\hline Pulmonary atresia & $27(33.3)$ & .929 & - \\
\hline Hypoplastic left heart syndrome & $16(20.0)$ & .821 & .586 \\
\hline VSD/PS & $12(14.8)$ & REF & REF \\
\hline Tricuspid atresia & $11(13.6)$ & .606 & - \\
\hline Other single ventricle & $14(17.3)$ & - & .875 \\
\hline Preoperative ventilation & $18(22.5)$ & .105 & .890 \\
\hline Extracardiac malformation & $16(20)$ & 1.000 & .794 \\
\hline Hematocrit, first in ICU & $42(38-46)$ & $.009 \dagger$ & .109 \\
\hline Platelet count, first in ICU & $176(96-260)$ & .609 & .823 \\
\hline Use of cardiopulmonary bypass & $55(68.8)$ & .644 & 1.000 \\
\hline Shunt type & - & - & .250 \\
\hline Norwood with m-BT shunt & $28(35.0)$ & .423 & - \\
\hline m-BT shunt & $39(48.8)$ & 1.000 & - \\
\hline Central shunt & $12(15.0)$ & REF & REF \\
\hline Shunt size & - & $.175^{*}$ & $.940^{*}$ \\
\hline 3 & $1(1.3)$ & - & - \\
\hline 3.5 & $45(57.7)$ & - & - \\
\hline 4 & 27 (34.6) & - & - \\
\hline 5 & $5(6.4)$ & - & - \\
\hline Pulmonary artery plasty & $10(12.5)$ & .186 & .444 \\
\hline Intraoperative volume of PRBCs transfused $\dagger$ & $100(78-129)$ & .573 & .948 \\
\hline Intraoperative volume balance & $27(0-70)$ & .441 & .946 \\
\hline Postoperative volume cell saver transfused $\ddagger$ & $36(28-54)$ & .721 & .144 \\
\hline Postoperative volume of PRBCs transfused $\ddagger$ & $15(10-24)$ & 1.000 & $.001 \dagger$ \\
\hline Postoperative volume of platelets transfused $\ddagger$ & $14(10-15)$ & .863 & .140 \\
\hline Postoperative volume of FFP transfused $\ddagger$ & $9(8-13)$ & 1.000 & 1.000 \\
\hline Initial postoperative $\mathrm{PaO}_{2}$ & $40(36-48)$ & .927 & $<.000 \dagger$ \\
\hline Inotrope score & $5(0-10)$ & 196 & $.039 \dagger$ \\
\hline Late operative era $\S$ & $19(23.8)$ & $<.000^{*}$ & 1.000 \\
\hline
\end{tabular}

Numbers represent means/medians (SD/IQR) for continuous variables and numbers (\%) for categoric variables. All $P$ values were calculated using univariable logistic regression, considering the effects of clustering by surgeon. $S D$, Standard deviation; $I Q R$, interquartile range; $S G A$, small for gestational age; VSD/PS, ventricular septal defect with pulmonary atresia; $I C U$, intensive care unit; $m-B T$, modified Blalock-Taussig shunt; $P R B C$, packed red blood cells; $F F P$, fresh-frozen plasma; $P a o_{2}$, arterial oxygen tension. ${ }^{*} P$ values were calculated using shunt size as a continuous variable. Shunt sizes were tested indexed to patient weight with similar results $(P=.312$ and $P=.876$, respectively). $\dagger P<.05$. $\ddagger$ Transfusion volumes of PRBCs, cell saver, and platelets, and FFP were measured as the total volume per kilogram transfused either in the operating room or in first 24 postoperative hours (or until shunt occlusion). Postoperative median volumes were calculated including only those patients who received PRBC $(n=11)$, platelet $(n=7)$, or FFP transfusions within the first 24 postoperative hours. §Late operative era is defined as an operation occurring on or after July 1, 2014.

intervention. The secondary outcome was 30-day mortality. No patients underwent transplantation.

\section{Statistical Analysis}

All statistical analyses were conducted in Stata software, version 13 (StataCorp LP, College Station, Tex). Clinical and demographic variables were described using standard summary statistics. To assess the marginal associations between independent variables and shunt occlusion or mortality, Fisher exact tests were used for categoric variables and $t$ tests or Wilcoxon rank-sum tests were used for continuous variables. Associations between covariates also were assessed.

Kaplan-Meier curves were used to assess the timing of all shunt occlusions to validate the assumption that shunt occlusion occurs as a 2-phase phenomenon (ie, early and late). Lowess plots were then used to determine whether the relationships between first postoperative hematocrit, and the outcomes of interest were best modeled as linear functions.
Univariable logistic regression was used. Model-based confidence intervals were constructed and hypothesis testing was performed using robust standard errors, with clusters corresponding to surgeons. On the basis of the results of the Kaplan-Meier curve, sensitivity analyses were conducted to assess the robustness of our results to changes in the definition of "early" shunt occlusion ( 24 vs 48 hours). To test the sensitivity of our results to the statistical modeling chosen, survival analyses were also conducted, examining first early shunt occlusion and mortality as primary end points and then all shunt occlusions. Additional sensitivity analyses were then conducted to assess the robustness of our results to changes in operative era; we repeated logistic analyses for mortality, including only patients undergoing operation in the early era, before the cluster of shunt occlusions were identified. Only 1 patient experienced shunt occlusion in the early operative era; thus, to avoid overfitting a model, similar analyses were not conducted for shunt occlusion. Because of the limited number of events, multivariable regression models were not included. 
TABLE 2. Time to shunt occlusion and patient characteristics

\begin{tabular}{llll}
\hline Patient no. & Time (h/d) & \multicolumn{1}{c}{ Cardiac diagnosis } & Procedure \\
\hline 1 & $2.0 \mathrm{~h}$ & PA, hypoplastic RV & $\mathrm{m}-\mathrm{BTS}$ \\
2 & $2.5 \mathrm{~h}$ & PA, TA, hypoplastic RV & $\mathrm{m}-\mathrm{BTS}$ \\
3 & $3.0 \mathrm{~h}$ & HLHS & Norwood/m-BTS \\
4 & $4.0 \mathrm{~h}$ & Heterotaxy, PA, discontinuous pulmonary arteries, TAPVR & Central \\
5 & $9.5 \mathrm{~h}$ & DORV, PS & $\mathrm{m}-\mathrm{BTS}$ \\
\hline 6 & $48 \mathrm{~h}$ & TOF & $\mathrm{m}-\mathrm{BTS}$ \\
\hline 7 & $10 \mathrm{~d}$ & HLHS & Norwood/m-BTS \\
8 & $10 \mathrm{~d}$ & HLHS & Norwood/m-BTS \\
9 & $12 \mathrm{~d}$ & TA, VSD & Norwood/m-BTS \\
10 & $18 \mathrm{~d}$ & HLHS & Norwood/m-BTS \\
11 & $23 \mathrm{~d}$ & HLHS & Norwood/m-BTS \\
12 & $25 \mathrm{~d}$ & Unbalanced AVC, PA, L-TGA & Central \\
\hline
\end{tabular}

$P A$, Pulmonary artery; $R V$, right ventricle; $m$-BTS, modified Blalock-Taussig shunt; TA, tricuspid atresia; $H L H S$, hypoplastic left heart syndrome; TAPVR, total anomalous pulmonary venous return; $D O R V$, double-outlet right ventricle; $P S$, pulmonary stenosis; $T O F$, tetralogy of Fallot; VSD, ventricular septal defect; $A V C$, atrioventricular canal; $L-T G A$, L-transposition of the great arteries.

In secondary analyses, scatter plots were used to graphically depict the first postoperative hematocrits of children who experienced early shunt occlusion or 30-day mortality in relation to their peers, and the results of the multivariable shunt occlusion and mortality models were graphed. The Fisher exact test was used to assess the association between early shunt occlusion and mortality. Finally, Spearman correlation and Wilcoxon rank-sum tests were used to explore the relationships between PRBC transfusion volumes in the first 24 postoperative hours (or until early shunt occlusion) and first postoperative hematocrit, shunt occlusion, and mortality.

\section{RESULTS}

Eighty infants met inclusion criteria. Nineteen infants underwent operation after July 2014. Median initial postoperative hematocrit was $41.7 \%$ (interquartile range [IQR], 37.9-46.0), with a range of 31.7 to 55.8 (Table 1).

\section{Early Shunt Occlusion}

Twelve infants $(15.0 \%)$ experienced shunt occlusion. Five patients $(6.3 \%)$ experienced shunt occlusion within the first 24 postoperative hours, meeting our definition of early occlusion (all of these at $<10$ hours). One occurred at 48 hours. The rest occurred on or after 10 postoperative days (Table 2 and Figure 1). Of the 5 early shunt occlusions, 4 of them occurred during or after 2014. No infant at our center receives any form of anticoagulation during the first 12 postoperative hours. Therefore, no infant was started on anticoagulation before early shunt occlusion.

We found that the association between early shunt occlusion and first postoperative hematocrit was best modeled as a linear function. In univariable analyses, early shunt occlusion was significantly associated with first postoperative hematocrit. The only other variable significantly associated with early occlusion was later operative era. Of note, average first postoperative hematocrit was significantly higher in the later operative era $(45.3 \%$ vs $41.5 \%, P=.021)$ (Figure 2 ). For every 5 additional percentage points of hematocrit, an infant's

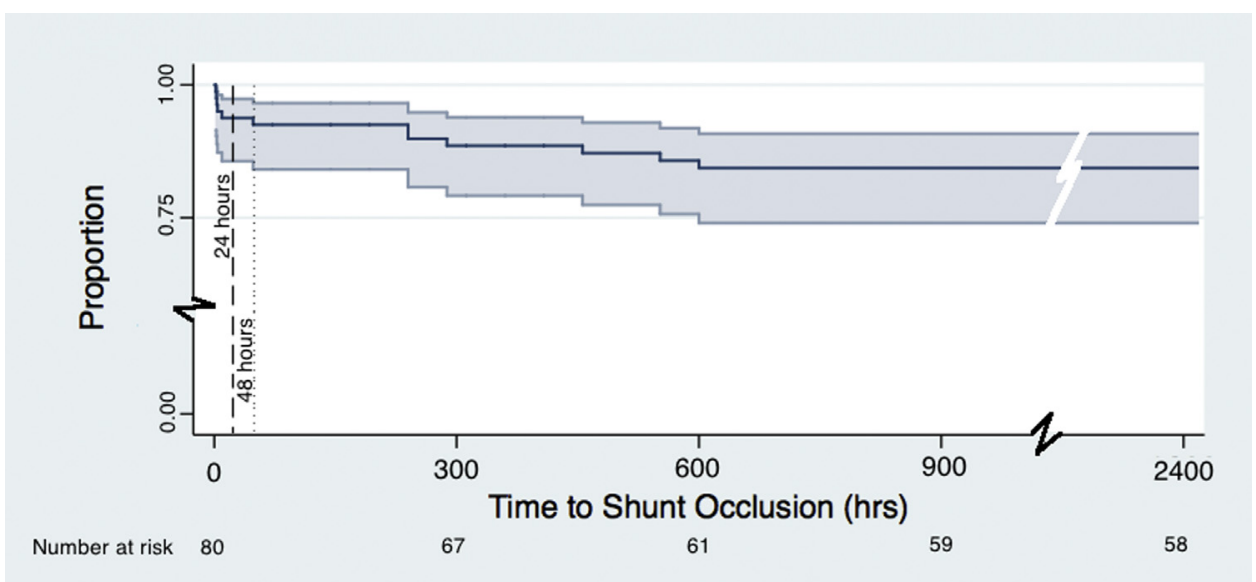

FIGURE 1. Postoperative shunt occlusion as a function of postoperative hours. Kaplan-Meier curve displays the timing of early and late postoperative shunt occlusion, with $95 \%$ confidence intervals. 


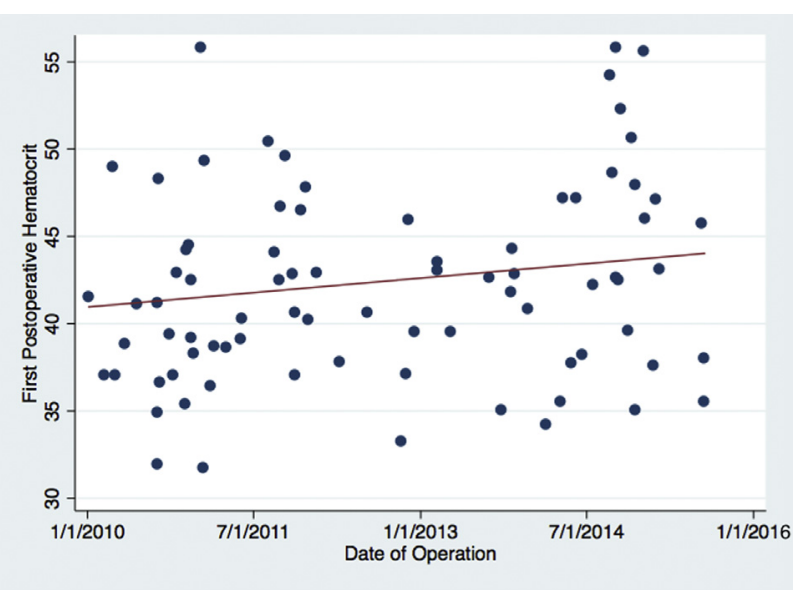

FIGURE 2. First postoperative hematocrit as a function of operative date. Scatterplot depicts the relationship between first postoperative hematocrit and operative date. A best-fit line is drawn in red.

odds of early shunt occlusion more than doubled (odds ratio $[\mathrm{OR}], 2.70 ; P=.009)$. In the later operative era, the odds of early shunt occlusion were 16.0 times the odds of early shunt occlusion in the early operative era $(P<.001)$. Adding the first postoperative hematocrit to a model already containing operative era modified (reduced) the magnitude of the era effect by $41 \%$. Expanding the definition of early shunt occlusion to include all occlusions within the first 48 hours yielded similar results (OR for the effects of first postoperative hematocrit: $2.24, P<.001$ ). Our results were similar when time-related methods were used. In survival analyses, for every 5 additional percentage points of hematocrit, an infant's hazard of early shunt occlusion also more than doubled (hazard ratio, 2.70; $P=.007$ ) and the hazard of any shunt occlusion nearly doubled (hazard ratio, 1.74; $P<.001)$.

\section{Mortality}

Six infants $(7.4 \%)$ died before discharge. Four infants $(5.0 \%)$ died within the first 30 postoperative days. No infant with early shunt occlusion died. Two infants with late shunt occlusion died (at 12 and 18 days of life). Causes of death are listed in Table 3.

In univariable analyses, only increased inotrope score and first postoperative $\mathrm{PaO}_{2}$ were associated with an increased risk of mortality. For every 5-point increase in vasoactive-inotrope score, the odds of mortality were 1.8 times greater $(\mathrm{OR}, 1.75 ; P=.021)$. For every 5-point increase in postoperative arterial oxygen tension, the odds of mortality were decreased by half (OR, $0.58 ; P<.001)$. Although no patient with a first postoperative hematocrit greater than $43 \%$ died within the first 30 postoperative days, no significant association was identified between hematocrit and 30-day mortality. Operative era was not independently associated with mortality. It should be noted that increased hematocrit was associated with increased inotrope score $(\rho=.349, P=.002)$, but first postoperative $\mathrm{PaO}_{2}$ was not $(P=.540)$. Repeating analyses using only patients who underwent operation in the early operative era revealed approximately identical results. Figure 3 uses a scatterplot to graphically depict the first postoperative hematocrit levels of children who experienced early shunt occlusion or mortality in relation to their peers and displays the differing effects of first postoperative hematocrit on early shunt occlusion and mortality. Results were similar when time-related methods were used.

\section{Intraoperative and Postoperative Transfusions}

Median intraoperative PRBC transfusion volume was $100 \mathrm{~mL} / \mathrm{kg}$ (IQR, 78-129); median fluid volume balance on bypass was $27 \mathrm{~mL} / \mathrm{kg}$ (IQR, 0-70); and median cell saver

TABLE 3. Causes and timing of mortality

\begin{tabular}{|c|c|c|c|c|c|c|}
\hline $\begin{array}{c}\text { Patient } \\
\text { identifier } \\
\end{array}$ & $\begin{array}{c}\text { Postoperative } \\
\text { day of death }\end{array}$ & Cardiac diagnosis & Procedure & $\begin{array}{c}\text { Early shunt } \\
\text { occlusion }\end{array}$ & $\begin{array}{c}\text { Late shunt } \\
\text { occlusion }\end{array}$ & Cause of death \\
\hline A & 12 & HLHS & Norwood/m-BTS & No & Yes & Late shunt occlusion \\
\hline $\mathrm{B}$ & 13 & HLHS & Norwood/m-BTS & No & No & $\begin{array}{l}\text { Well until POD 13; autopsy suggested } \\
\text { acute myocardial infarction }\end{array}$ \\
\hline $\mathrm{C}$ & 17 & $\begin{array}{l}\text { Heterotaxy, RVDAVC, } \\
\text { dTGA, TAPVR }\end{array}$ & $\begin{array}{l}\text { m-BTS, bilateral PA plasty, } \\
\text { TAPVR repair }\end{array}$ & No & No & $\begin{array}{l}\text { Arrested POD 1; placed on ECMO; } \\
\text { cardiac function remained poor; } \\
\text { withdrew care }\end{array}$ \\
\hline $\mathrm{D}$ & 18 & TA, VSD & Norwood/m-BTS & No & Yes & Late shunt occlusion \\
\hline $\mathrm{E}$ & 31 & VSD, PS, DORV & m-BTS & No & No & $\begin{array}{l}\text { Transfusion reaction POD } 0 \text { with } \\
\text { associated arrest with significant } \\
\text { sequelae; made DNR }\end{array}$ \\
\hline $\mathrm{F}$ & 131 & HLHS & $\begin{array}{l}\text { Norwood/m-BTS, PA } \\
\text { debanding, bilateral } \\
\text { PA plasty }\end{array}$ & No & No & $\begin{array}{l}\text { Micropremature infant; remained in } \\
\text { hospital through Glenn; thrombus } \\
\text { in Glenn circuit }\end{array}$ \\
\hline
\end{tabular}

$\overline{H L H S}$, Hypoplastic left heart syndrome; $m$-BTS, modified Blalock-Taussig shunt; $P O D$, postoperative day; RVDAVC, right ventricle dominant atrioventricular canal; $d T G A$, dextro-transposition of the great arteries; TAPVR, total anomalous pulmonary venous return; $P A$, pulmonary artery; $E C M O$, extracorporeal membrane oxygenation; $T A$, tricuspid atresia; VSD, ventricular septal defect; $P S$, pulmonary stenosis; DORV, double-outlet right ventricle; $D N R$, do not resuscitate. 


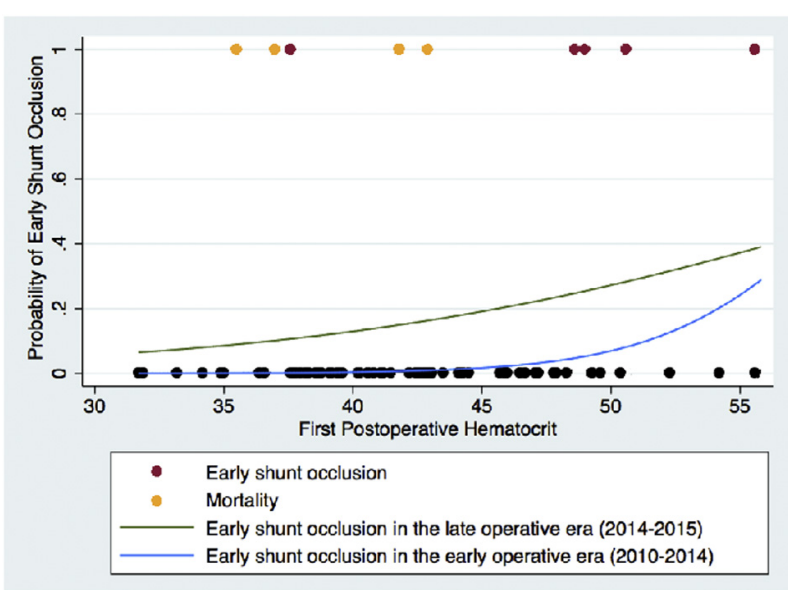

FIGURE 3. First postoperative hematocrit and early postoperative shunt occlusion. In this figure, the probability of early postoperative shunt occlusion is depicted as functions of first postoperative hematocrit for the early (2010-2014; blue) and late (2014-2015; green) operative eras. Models are superimposed on a scatter plot, with red circles representing infants who experienced early postoperative shunt occlusion, orange circles representing infants who died within the first 30 postoperative days, and black circles representing infants who experienced neither early postoperative shunt occlusion nor 30-day mortality.

transfusion volume coming off bypass was $36 \mathrm{~mL} / \mathrm{kg}$ (IQR, 28-54). PRBC, cell saver transfusion volumes, and fluid volume balance were not significantly associated with first postoperative hematocrit, early shunt occlusion, or mortality (Table 1).

In the first 24 postoperative hours, $13.8 \%(\mathrm{n}=11)$ of infants received PRBC transfusions, 8.8\% $(\mathrm{n}=7)$ received platelets, and 5.0\% $(\mathrm{n}=4)$ received $\mathrm{FFP} /$ cryoprecipitate. Among those receiving PRBC transfusions, the median transfusion volume within the first 24 postoperative hours (or until shunt occlusion) was $15 \mathrm{~mL} / \mathrm{kg}$ (IQR, 10-24; range, 4-67). Among those receiving platelet transfusions, the median transfusion volume within the first 24 postoperative hours (or until shunt occlusion) was $14 \mathrm{~mL} / \mathrm{kg}$ (IQR, 10-15; range, 5-20). Among those receiving FFP/cryoprecipitate, the median FFP transfusion volume within the first 24 postoperative hours (or until shunt occlusion) was $9 \mathrm{~mL} / \mathrm{kg}$ (IQR, 8-13; range, 8-17). Lower first postoperative hematocrit was associated with a higher PRBC transfusion volume $(P=.045)$, but not a higher volume of platelets or FFP. Higher postoperative PRBC transfusion volumes, but not platelet or FFP volumes, were associated with an increased odds of mortality $(P=.001)$. PRBC, platelet, and FFP transfusion volumes within the first 24 postoperative hours were not significantly associated with early shunt occlusion (Table 1).

\section{DISCUSSION}

Neonatal shunt occlusion remains a vexing problem for infants with cyanotic heart disease. In this retrospective study of 80 infants undergoing systemic to pulmonary artery shunt placement, we found higher first postoperative hematocrit to be associated with early shunt occlusion. Before promoting reduced target postoperative hematocrits, we also tested the effects of hematocrit on a more robust outcome, 30-day mortality. In univariable analyses, we found no association between first postoperative hematocrit and death—at least in an era when all children at our center who experienced early shunt occlusion were recovered.

Data are limited on ideal hematocrit targets for children after cardiac surgery, let alone for infants with cyanotic heart disease. Previous randomized controlled trials on intraoperative target hematocrits for children undergoing congenital heart surgery reported improved short- and long-term outcomes with lower hematocrit levels, but excluded children with single ventricles and did not discuss target postoperative values. ${ }^{12}$ One study by Guzzetta and colleagues ${ }^{13}$ looked specifically at the effects of first postoperative hematocrit on shunt occlusion. This study found no significant effect of first postoperative hematocrit on shunt occlusion; however, it lumped all in-hospital shunt occlusions into a single outcome, including those occurring 9 days postoperatively, regardless of postoperative transfusion status. ${ }^{13}$ Two studies looking at the effects of postoperative hematocrit on mortality and length of stay (among other outcomes) for shunted neonates found no effect. ${ }^{13,14}$ Another study by Tweddell and colleagues ${ }^{14}$ found a negative effect of increased postoperative hemoglobin levels on mortality in univariable analyses, but no effect in multivariable analyses. ${ }^{14}$ All 3 of these studies looked at average hematocrit/hemoglobin levels over a period of days to weeks, however, rather than the first postoperative hematocrit, thus conflating the effects of baseline hematocrit and subsequent transfusions performed in response. ${ }^{15,16}$

There is strong evidence to suggest that there are detrimental effects of transfusions in critically ill individuals. The adult literature has consistently shown conservative red blood cell transfusion strategies to be at least as effective as more liberal approaches, and many have described associations with reduced mortality, postoperative infections, immune modulation, and endorgan dysfunction, as well as transfusion-related acute lung injury, transfusion-related circulatory overload, and hemolytic transfusion reactions. ${ }^{17-21}$ A subgroup analysis from the leading adult randomized controlled trial found a conservative transfusion strategy to be associated with reduced mortality and end-organ dysfunction among adults admitted with cardiac disease. ${ }^{19}$ Additional studies in adults after coronary artery bypass surgery have demonstrated associations between increased transfusion volumes and increased mortality, infections, prolonged ventilation, renal failure, neurologic dysfunction, and total hospital costs. ${ }^{22-25}$ A 2015 study examined specifically graft occlusion after 
coronary artery bypass surgery and described a $20 \%$ increased hazard of graft occlusion in patients who received transfusions, after adjusting for other patient covariates. ${ }^{26}$

Studies in pediatrics are more limited. However, those that exist have found similar results. Investigators from the Transfusion Requirements in the Pediatric Intensive Care Unit study, the only randomized controlled trial of PRBC transfusions in children, confirmed that a restrictive transfusion strategy was safe in children, although this study failed to demonstrate a protective effect. ${ }^{27} \mathrm{~A}$ subgroup analysis found similar results in children after cardiac surgery, although this analysis excluded neonates and children with cyanotic heart disease. ${ }^{28}$ Salvin and colleagues, ${ }^{29}$ in a retrospective study in 2011, reported that PRBC transfusions were an independent risk factor for prolonged length of stay for children who underwent cardiac surgery, including infants with cyanotic heart disease. Stratified analyses on this subpopulation were not performed. $^{29}$

To the best of our knowledge, our study represents the first time researchers have looked specifically at the associations between first postoperative hematocrit and early shunt occlusion or mortality. Our data suggest that lower target postoperative hematocrits yield optimal outcomes. One might hypothesize, as we did, that increased postoperative hematocrit increases blood viscosity, thereby predisposing patients to shunt occlusion. Although we were unable to detect significant associations with mortality, one might further hypothesize that lower is not always better and that exceptionally low hematocrit levels might be associated with an inability to tolerate increased myocardial demands in the postoperative cyanotic neonate or that reduced hematocrit levels are association with increased transfusion volumes and increased transfusions carry risks, consistent with much of the literature cited earlier. ${ }^{17-26,29}$

Our study also raises the perpetual question: What is the ideal perioperative prophylactic antithrombotic therapy for these patients? At our center, in keeping with the guidelines of the American Heart Association and the American College of Chest Physicians, we initiate aspirin therapy 12 hours postoperatively, if hemostasis has been obtained. All of our early shunt occlusions, however, occurred at less than 10 hours postoperatively. The American Heart Association guidelines state that "it is reasonable to initiate a continuous low-dose heparin infusion" in these patients (Level of Evidence C), ${ }^{30}$ but the American College of Chest Physicians guidelines recommend against this. ${ }^{31}$ Both guidelines acknowledge that there are no clear data on the utility or risks of perioperative heparin for shunted neonates. In fact, although the most often cited study in favor of heparin use for Blalock-Taussig shunts reported a reduction in the risk of early shunt occlusion from $3.4 \%$ to $1.4 \%$, this difference failed to meet statistical significance $(P=.294))^{32}$ A national database study examining best practices associated with systemic-to-pulmonary artery shunts found no difference in the use of postoperative heparin between centers with low or high incidences of shunt failure. ${ }^{33}$ These studies did not consider differences in postoperative hematocrit. Large-scale, thoughtful investigations are clearly needed to determine the best perioperative management.

In our study, it is notable that patients' first postoperative hematocrits increased in the later operative era. We analyzed our practice in detail, and there have been no intentional changes in patient management over the study period. Specifically, there was no change in target hematocrit levels preoperatively, intraoperatively, or perioperatively. The only change we have identified at our center was a switch in the point of care analyzer in 2013. In that year, our center switched from the i-STAT portable analyzer (Abbott, Princeton, NJ) to the epoc Blood Analysis System (Alere, Waltham, Mass). In response to our investigations, our cardiac anesthesiologists have been asked not to transfuse any postoperative shunted neonate when the point of care analyzer reports a hematocrit level of $35 \%$ or higher. Hematocrits are then repeated in our clinical laboratory, using a Sysmex XN9000 analyzer, immediately on a patient's return to the cardiac intensive care unit. We also established a protocol for the initiation of partial exchange transfusions for patients with hematocrit levels greater than $55 \%$. Given the lack of evidence on prophylactic heparin infusions described earlier, we have not changed our routine anticoagulation practices. For patients with lower hematocrit levels who are more cyanotic than expected postoperatively, we take an individualized approach. Our initial management includes a diagnostic echocardiogram, nitric oxide, oxygen, and initiation of a heparin bolus and infusion. In some patients, inotropic support is also escalated. If symptoms do not resolve and acute shunt occlusion is not highly suspected, cautious transfusions are sometimes considered.

\section{Study Limitations}

Our study has a few notable limitations, and the target hematocrit levels described should be interpreted with caution. Most important, our study is retrospective and conducted on a limited number of patients at a single center. In addition, although patients were cared for by a small team of practitioners, there was no prescribed management protocol during the operative era. Fluid management at our center is relatively consistent, but transfusion thresholds and other aspects of care vary to some degree between providers. Thus, although it is tempting to speculate on mechanisms of action between hematocrit levels and shunt occlusion, one cannot assume causality and future studies are needed to determine ideal target thresholds. We must further point out that it is possible that the relationships 
between hematocrit and both shunt occlusion and mortality are more complex than our models allow us to describe. For example, there might be interactions between hematocrit and other patient factors, such as baseline blood pressure or systemic venous saturations, such that different hematocrit levels are optimal in different patient settings. In addition, other coagulation parameters (eg, prothrombin time and partial thromboplastin time) are not routinely obtained in the immediate postshunt period at our institution, and so their effects could not be assessed. Larger investigations are needed to explore these possibilities. Finally, during the study period, no children at our center who experienced early shunt occlusion died. This reduces the generalizability of any specific target hematocrit identified, particularly when considered by centers with lower rates of rescue.

\section{CONCLUSIONS}

We found that higher postoperative hematocrit levels are associated with early shunt occlusions in infants undergoing primary systemic to pulmonary artery shunt placement. Given the small sample size, these conclusions should be considered as preliminary data only; larger, multicenter studies are needed to validate these findings and to determine ideal postoperative hematocrit targets.

\section{Conflict of Interest Statement}

B.R.A. receives salary support from the National Center for Advancing Translational Sciences (KL2 TR000081). J.M.D. receives salary support from the National Institute of Allergy and Infections Disease (T32 AI007531). All other authors have nothing to disclose with regard to commercial support.

The authors thank Michael Brewer, MS, CCP, for assistance in data acquisition.

\section{References}

1. Wells WJ, Yu RJ, Batra AS, Monforte H, Sintek C, Starnes VA. Obstruction in modified Blalock shunts: a quantitative analysis with clinical correlation. Ann Thorac Surg. 2005;79:2072-6.

2. Lamberti JJ, Carlisle J, Waldman JD, Lodge FA, Kirkpatrick SE, George L, et al. Systemic-pulmonary shunts in infants and children. Early and late results. J Thorac Cardiovasc Surg. 1984;88:76-81.

3. Tsai KT, Chang CH, Lin PJ. Modified Blalock-Taussig shunt: statistical analysis of potential factors influencing shunt outcome. J Cardiovasc Surg (Torino). 1996; 37:149-52.

4. Fermanis GG, Ekangaki AK, Salmon AP, Keeton BR, Shore DF, Lamb RK, et al. Twelve year experience with the modified Blalock-Taussig shunt in neonates. Eur J Cardiothorac Surg. 1992;6:586-9.

5. Alkhulaifi AM, Lacour-Gayet F, Serraf A, Belli E, Planche C. Systemic pulmonary shunts in neonates: early clinical outcome and choice of surgical approach. Ann Thorac Surg. 2000;69:1499-504.

6. Ilbawi MN, Grieco J, DeLeon SY, Idriss FS, Muster AJ, Berry TE, et al. Modified Blalock-Taussig shunt in newborn infants. J Thorac Cardiovasc Surg. 1984;88: 770-5.

7. Bartram U, Grunenfelder J, Van Praagh R. Causes of death after the modified Norwood procedure: a study of 122 postmortem cases. Ann Thorac Surg. 1997;64:1795-802.
8. Sen S, Duchon J, Lampl B, Aspelund G, Bacha E, Krishnamurthy G. Heterotaxy syndrome infants are at risk for early shunt failure after Ladd procedure. Ann Thorac Surg. 2015;99:918-25.

9. Tokarev AA, Butylin AA, Ataullakhanov FI. Platelet adhesion from shear blood flow is controlled by near-wall rebounding collisions with erythrocytes. Biophys J. 2011;100:799-808.

10. Chen H, Angerer JI, Napoleone M, Reininger AJ, Schneider SW, Wixforth A, et al. Hematocrit and flow rate regulate the adhesion of platelets to von Willebrand factor. Biomicrofluidics. 2013;7:64113.

11. Gaies MG, Gurney JG, Yen AH, Napoli ML, Gajarski RJ, Ohye RG, et al. Vasoactive-inotropic score as a predictor of morbidity and mortality in infants after cardiopulmonary bypass. Pediatr Crit Care Med. 2010;11: 234-8.

12. Wypij D, Jonas RA, Bellinger DC, Del Nido PJ, Mayer JE Jr, Bacha EA, et al. The effect of hematocrit during hypothermic cardiopulmonary bypass in infant heart surgery: results from the combined Boston hematocrit trials. J Thorac Cardiovasc Surg. 2008;135:355-60.

13. Guzzetta NA, Foster GS, Mruthinti N, Kilgore PD, Miller BE, Kanter KR. In-hospital shunt occlusion in infants undergoing a modified Blalock-Taussig shunt. Ann Thorac Surg. 2013;96:176-82.

14. Tweddell JS, Ghanayem NS, Mussatto KA, Mitchell ME, Lamers LJ, Musa NL, et al. Mixed venous oxygen saturation monitoring after stage 1 palliation for hypoplastic left heart syndrome. Ann Thorac Surg. 2007;84: 1301-11.

15. Gupta P, King C, Benjamin L, Goodhart T, Robertson MJ, Gossett JM, et al. Association of hematocrit and red blood cell transfusion with outcomes in infants undergoing Norwood operation. Pediatr Cardiol. 2015;36:1212-8.

16. Dasgupta R, Parsons A, McClelland S, Morgan E, Robertson MJ, Noel TR, et al. Association of haematocrit and red blood cell transfusion with outcomes in infants with shunt-dependent pulmonary blood flow and univentricular physiology. Blood Transfus. 2015;13:417-22.

17. Hebert PC, Wells G, Blajchman MA, Marshall J, Martin C, Pagliarello G, et al. A multicenter, randomized, controlled clinical trial of transfusion requirements in critical care. Transfusion Requirements in Critical Care Investigators, Canadian Critical Care Trials Group. N Engl J Med. 1999; 340:409-17.

18. Corwin HL, Gettinger A, Pearl RG, Fink MP, Levy MM, Abraham E, et al. The CRIT Study: anemia and blood transfusion in the critically ill-current clinical practice in the United States. Crit Care Med. 2004; 32:39-52.

19. Hebert PC, Blajchman MA, Cook DJ, Yetisir E, Wells G, Marshall J, et al. Do blood transfusions improve outcomes related to mechanical ventilation? Chest. 2001;119:1850-7.

20. Muszynski J, Nateri J, Nicol K, Greathouse K, Hanson L, Hall M. Immunosuppressive effects of red blood cells on monocytes are related to both storage time and storage solution. Transfusion. 2012;52:794-802.

21. Li G, Rachmale S, Kojicic M, Shahjehan K, Malinchoc M, Kor DJ, et al. Incidence and transfusion risk factors for transfusion-associated circulatory overload among medical intensive care unit patients. Transfusion. 2011;51: 338-43.

22. Murphy GJ, Reeves BC, Rogers CA, Rizvi SI, Culliford L, Angelini GD. Increased mortality, postoperative morbidity, and cost after red blood cell transfusion in patients having cardiac surgery. Circulation. 2007;116: 2544-52.

23. Chelemer SB, Prato BS, Cox PM Jr, O'Connor GT, Morton JR. Association of bacterial infection and red blood cell transfusion after coronary artery bypass surgery. Ann Thorac Surg. 2002;73:138-42.

24. Koch CG, Li L, Duncan AI, Mihaljevic T, Cosgrove DM, Loop FD, et al. Morbidity and mortality risk associated with red blood cell and blood-component transfusion in isolated coronary artery bypass grafting. Crit Care Med. 2006;34:1608-16.

25. Koch CG, Li L, Duncan AI, Mihaljevic T, Loop FD, Starr NJ, et al. Transfusion in coronary artery bypass grafting is associated with reduced long-term survival. Ann Thorac Surg. 2006;81:1650-7.

26. Engoren M, Schwann TA, Jewell E, Neill S, Benedict P, Likosky DS, et al. Is transfusion associated with graft occlusion after cardiac operations? Ann Thorac Surg. 2015;99:502-8.

27. Lacroix J, Hebert PC, Hutchison JS, Hume HA, Tucci M, Ducruet T, et al. Transfusion strategies for patients in pediatric intensive care units. $N$ Engl J Med. 2007;356:1609-19. 
28. Willems A, Harrington K, Lacroix J, Biarent D, Joffe AR, Wensley D, et al. Comparison of two red-cell transfusion strategies after pediatric cardiac surgery: a subgroup analysis. Crit Care Med. 2010;38:649-56.

29. Salvin JW, Scheurer MA, Laussen PC, Wypij D, Polito A, Bacha EA, et al. Blood transfusion after pediatric cardiac surgery is associated with prolonged hospital stay. Ann Thorac Surg. 2011;91:204-10.

30. Giglia TM, Massicotte MP, Tweddell JS, Barst RJ, Bauman M, Erickson CC, et al. Prevention and treatment of thrombosis in pediatric and congenital heart disease: a scientific statement from the American Heart Association. Circulation. 2013; 128:2622-703

31. Monagle P, Chan AK, Goldenberg NA, Ichord RN, Journeycake JM, Nowak-Gottl U, et al. Antithrombotic therapy in neonates and children: Antithrombotic Therapy and Prevention of Thrombosis, 9th ed: American
College of Chest Physicians Evidence-Based Clinical Practice Guidelines Chest. 2012;141:e737S-801S.

32. Al Jubair KA, Al Fagih MR, Al Jarallah AS, Al Yousef S, Ali Khan MA Ashmeg A, et al. Results of 546 Blalock-Taussig shunts performed in 478 patients. Cardiol Young. 1998;8:486-90.

33. Heidari-Bateni G, Norouzi S, Hall M, Brar A, Eghtesady P. Defining the best practice patterns for the neonatal systemic-to-pulmonary artery shunt procedure. J Thorac Cardiovasc Surg. 2014;147:869-73.e3.

Key Words: hematocrit, Norwood, occlusion, shunt, single ventricle, transfusion

Readers who found these articles interesting may also like to read the following papers found in recent and future issues of our sister publications, Seminars in Thoracic and Cardiovascular Surgery and Operative Techniques in Thoracic and Cardiovascular Surgery!

\section{Congenital: Perioperative Management}

The Effect of Noncardiac and Genetic Abnormalities on Outcomes Following Neonatal Congenital Heart Surgery Bahaaldin Alsoufi. Semin Thoracic Surg 2016:105-14.

God is in the Detail: The Effect of Noncardiac and Genetic Abnormalities on Outcomes Following Neonatal Congenital Heart Surgery Scott M. Bradley. Semin Thoracic Surg 2016:118-19. 